\title{
Childhood abuse and neglect in relation to the presence and persistence of psychotic and depressive symptomatology
}

Citation for published version (APA):

van Dam, D. S., van Nierop, M., Viechtbauer, W., Velthorst, E., van Winkel, R., Bruggeman, R., Cahn, W., de Haan, L., Kahn, R. S., Meijer, C. J., Myin-Germeys, I., van Os, J., \& Wiersma, D. (2015). Childhood abuse and neglect in relation to the presence and persistence of psychotic and depressive symptomatology. Psychological Medicine, 45(7), 1363-1377. https://doi.org/10.1017/S0033291714001561

Document status and date:

Published: 01/05/2015

DOI:

10.1017/S0033291714001561

Document Version:

Publisher's PDF, also known as Version of record

Document license:

Taverne

Please check the document version of this publication:

- A submitted manuscript is the version of the article upon submission and before peer-review. There can be important differences between the submitted version and the official published version of record.

People interested in the research are advised to contact the author for the final version of the publication, or visit the DOI to the publisher's website.

- The final author version and the galley proof are versions of the publication after peer review.

- The final published version features the final layout of the paper including the volume, issue and page numbers.

Link to publication

\footnotetext{
General rights rights.

- You may freely distribute the URL identifying the publication in the public portal. please follow below link for the End User Agreement:

www.umlib.nl/taverne-license

Take down policy

If you believe that this document breaches copyright please contact us at:

repository@maastrichtuniversity.nl

providing details and we will investigate your claim.
}

Copyright and moral rights for the publications made accessible in the public portal are retained by the authors and/or other copyright owners and it is a condition of accessing publications that users recognise and abide by the legal requirements associated with these

- Users may download and print one copy of any publication from the public portal for the purpose of private study or research.

- You may not further distribute the material or use it for any profit-making activity or commercial gain

If the publication is distributed under the terms of Article $25 \mathrm{fa}$ of the Dutch Copyright Act, indicated by the "Taverne" license above, 


\title{
Childhood abuse and neglect in relation to the presence and persistence of psychotic and depressive symptomatology
}

\author{
D. S. van Dam $^{1} \mathbf{t}$, M. van Nierop ${ }^{2} \mathbf{t}$, W. Viechtbauer ${ }^{2}$, E. Velthorst ${ }^{1,7}$, R. van Winkel ${ }^{2,3}$ and Genetic \\ Risk and Outcome of Psychosis (GROUP) investigators: R. Bruggeman ${ }^{4}$, W. Cahn ${ }^{5}$, L. de Haan ${ }^{1}$, \\ R. S. Kahn ${ }^{5}$, C. J. Meijer ${ }^{1 *}$, I. Myin-Germeys ${ }^{2}$, J. van $\mathrm{Os}^{2,6}$ and D. Wiersma ${ }^{4}$ \\ ${ }^{1}$ Department of Psychiatry, Academic Medical Center, University of Amsterdam, The Netherlands \\ ${ }^{2}$ Maastricht University Medical Center, South Limburg Mental Health Research and Teaching Network, EURON, Maastricht, The Netherlands \\ ${ }^{3}$ University Psychiatric Center, Katholieke Universiteit Leuven, Kortenberg, Belgium \\ ${ }^{4}$ Department of Psychiatry, University Medical Center Groningen, University of Groningen, The Netherlands \\ ${ }^{5}$ Department of Psychiatry, Rudolf Magnus Institute of Neuroscience, University Medical Center Utrecht, The Netherlands \\ ${ }^{6}$ Department of Psychosis Studies, Institute of Psychiatry, King's College London, UK \\ ${ }^{7}$ Icahn School of Medicine at Mount Sinai, Departments of Psychiatry and Preventive Medicine, New York, USA
}

Background. The association between childhood trauma and psychotic and depressive symptomatology is well established. However, less is known about the specificity and course of these symptoms in relation to childhood trauma.

Method. In a large sample $(n=2765)$ of patients with psychosis $(n=1119)$, their siblings $(n=1057)$ and controls $(n=589)$, multivariate (mixed-effects) regression analyses with multiple outcomes were performed to examine the association between childhood trauma and psychotic and depressive symptomatology over a 3-year period.

Results. A dose-response relationship was found between childhood trauma and psychosis. Abuse was more strongly associated with positive symptoms than with negative symptoms whereas the strength of the associations between neglect and positive and negative symptoms was comparable. In patients, similar associations between childhood trauma and psychotic or depressive symptoms were found, and in siblings and controls, stronger associations were found between trauma and depressive symptomatology. Childhood trauma was not related to a differential course of symptoms over a 3-year time period.

Conclusions. In congruence with earlier work, our findings suggest that childhood trauma, and abuse in particular, is associated with (subthreshold) psychosis. However, childhood trauma does not seem to be associated with a differential course of symptoms, nor does it uniquely heighten the chance of developing (subthreshold) psychotic symptomatology. Our results indicate that trauma may instead contribute to a shared vulnerability for psychotic and depressive symptoms.

Received 31 October 2013; Revised 17 April 2014; Accepted 10 June 2014; First published online 17 July 2014

Key words: Abuse, childhood trauma, depression, neglect, psychosis, symptom course.

\section{Introduction}

The association between childhood abuse and neglect (hereafter childhood trauma) and psychosis is well established. A growing number of prospective cohort studies, case-control and cross-sectional studies have found strong associations between childhood trauma and the development of psychotic disorders (Varese et al. 2012). However, in studies examining this

\footnotetext{
* Address for correspondence: C. J. Meijer, M.Sc., Ph.D., Department of Psychiatry, Early Psychosis Section, Academic Medical Center, Meibergdreef 5, Room PA1-136, 1105 AZ Amsterdam, The Netherlands.

(Email: c.j.meijer@amc.uva.nl)

t These authors contributed equally to this work.
}

association, there are still important issues that have received limited attention.

One of these issues concerns the specificity of type of childhood trauma in relation to different symptom domains of psychosis. That is, various types of early trauma may have different effects on neurodevelopmental, social and emotional development (Glaser, 2000) and are therefore possibly associated with different symptoms (Bentall \& Fernyhough, 2008; Bentall et al. 2012). A study conducted by Heins et al. (2011) addressed this issue by comparing effect sizes of abuse and neglect in relation to distinct psychosis symptom domains in patients, siblings and controls. They found the strongest associations between abuse and (subthreshold) positive symptoms whereas neglect was more strongly related to general psychopathology. 
Although the study of Heins et al. (2011) has increased our understanding of specific associations between childhood trauma and psychosis, to date there are more sophisticated statistical techniques to assess the influence of childhood trauma on different, yet often co-occurring, symptom clusters (e.g. positive, negative and general symptoms in psychotic disorders). Specifically, multivariate (mixed-effects) regression allows examination of the unique influence of childhood trauma in relation to multiple symptom domains, and direct comparison of which association is stronger (Hox, 2010).

It is also unclear to what extent childhood trauma specifically increases the chance of developing psychotic symptoms in comparison to other psychiatric symptoms. Childhood trauma is not only related to a greater risk of developing psychotic disorders but has also been linked to a variety of other psychiatric disorders later in life, such as depression, affective psychosis and different anxiety disorders including posttraumatic stress disorder (Matheson et al. 2013). An important question in this regard is whether childhood trauma uniquely heightens the chance of developing (subthreshold) psychotic symptomatology in persons who are genetically vulnerable to developing psychotic symptoms.

Another issue that needs evaluation is the association between childhood trauma and course of symptoms over time in patients with psychosis. General population studies suggest that childhood trauma not only predicts the development of subclinical psychotic symptoms but also is related to higher symptom levels over time (Cougnard et al. 2007; De Loore et al. 2007; Schreier et al. 2009; Arseneault et al. 2011; Mackie et al. 2011; Wigman et al. 2011; Kelleher et al. 2013). However, the literature on the association between childhood trauma and course of symptoms in patients with psychosis is sparse and results are contradictory (Greenfield et al. 1994; Lysaker et al. 2005). Although it is known that childhood trauma is related to heightened symptoms levels (Ross et al. 1994; Conus et al. 2010; Heins et al. 2011), it is not clear how these symptoms evolve over time.

The literature on the impact of childhood trauma on the course of symptoms in affective disorders is more consistent. Although only a few studies have investigated the association between childhood trauma and symptomatology over time, it has been reported that the presence of childhood trauma leads to higher levels of manic, depressive and anxiety symptoms over time in patients with bipolar (Leverich et al. 2002; Neria et al. 2005) and depressive disorder (Zlotnick et al. 1995; Hovens et al. 2012).

Investigating childhood trauma in relation to the course of symptoms over time is required to estimate the long-term impact of trauma on symptomatology. It is also of interest to examine whether childhood trauma is related to a differential course of symptoms (that is, whether symptoms in the trauma group increase or decrease to a similar extent compared to the non-trauma group), which, to the best our knowledge, no study has yet examined.

The aims of the present study were (i) to replicate the study of Heins et al. (2011) in an independent and larger sample of patients with psychosis, siblings and control subjects by using more advanced statistical methods accounting for the unique influence of childhood trauma in relation to multiple symptom domains, (ii) to examine whether childhood trauma is more strongly related to (subthreshold) psychotic than affective symptoms in subjects at genetic risk of psychosis, and (iii) to examine whether childhood trauma is related to a differential course of symptoms.

\section{Method}

\section{Subjects}

This research was part of a longitudinal observational study called the 'Genetic Risk and Outcome of Psychosis Project' (GROUP; Korver et al. 2012). The GROUP study investigates the vulnerability and resilience factors for the development of a psychotic disorder and the variation in the course of the illness. The full sample consists of patients $(n=1119)$, their siblings $(n=1057)$ and a control group $(n=589)$.

In representative geographical areas in The Netherlands and Belgium, patients were identified through clinicians working in regional psychotic disorder services, whose caseload was screened for inclusion criteria. Subsequently, a group of patients presenting at these services either as out-patients or in-patients were recruited for the study. Patients were recruited from four university departments of psychiatry in The Netherlands (Amsterdam, Groningen, Maastricht and Utrecht) and affiliated mental health care institutions. Heins et al. (2011) used the sample that was recruited in Maastricht (patients: $n=306$; siblings: $n=289$; controls: $n=244$ ). Thus, for the replication analyses, only subjects recruited from the other sites were used: Amsterdam (patients: $n=283$; siblings: $n=$ 258; controls: $n=104$ ), Groningen (patients: $n=287$; siblings: $n=273$; controls: 84 ) and Utrecht (patients: $n=243$; siblings: $n=237$; controls: $n=157$ ). For all other analyses, the full sample (including the Maastricht sample) was used.

\section{Inclusion criteria}

Patients were eligible to be included in the study if: (1) they were aged between 16 and 50 years, (2) they met 
DSM-IV criteria for a non-affective psychotic disorder [schizophrenia, schizophreniform disorder, schizoaffective disorder, delusional disorder, psychotic disorder not otherwise specified (NOS)], (3) their first contact with mental health care had occurred less than 10 years ago, (4) they were able to communicate in the Dutch language and (5) they had one or more siblings volunteering to participate in the research. Except for the DSM-IV and mental health care criteria, similar criteria were applied to the siblings and the controls.

Control subjects were selected through random mailings to addresses in the catchment areas of the cases. The majority of mental health care services in The Netherlands and a substantial number of mental health services in Dutch-speaking Belgium took part in the GROUP study. Representativeness of the control sample was maximized as the control sample (i) was collected from the same geographical area as the case in the relevant mental health service, (ii) was sufficiently large to allow for chance variation, and (iii) was frequency matched in age and sex distribution to the siblings.

\section{Exclusion criteria}

Subjects were excluded if their estimated level of intelligence (IQ) was below 70, as assessed with the short form of the Wechsler Adult Intelligence Scale (WAIS-III; Wechsler, 1997). When siblings fulfilled criteria for a psychotic disorder, they were included in the patient group. Controls were excluded if they had a history of psychosis or if they had a first-degree family member diagnosed with a psychotic disorder. To confirm absence of a family history of psychotic disorders in the controls, the Family Interview for Genetic Studies (FIGS; Maxwell, 1992) was conducted, with the control as informant, to establish absence of first-degree relatives with a psychotic disorder.

\section{Measures}

The Comprehensive Assessment of Symptoms and History (CASH; Andreasen et al. 1992) or the Schedules for Clinical Assessment in Neuropsychiatry (SCAN 2.1; Wing et al. 1990) (Groningen site) was used to assess DSM-IV diagnosis at baseline and at the 3-year follow-up. The CASH includes the Scale for the Assessment of Positive Symptoms (SAPS, with 34 items measured on a Likert scale ranging from $0=$ absent to 5=severe; Andreasen, 1984) and the 21-item Scale for the Assessment of Negative Symptoms (SANS; Andreasen, 1982). The SCAN is a semi-structured computer-based interview to assess psychiatric symptoms. Level of functioning was assessed by the Global Assessment of Functioning (GAF) scale (APA, 2000). This scale defines a symptom score (GAF-S) and a functioning score (GAF-F), reflecting the severity of symptoms and the level of daily functioning.

\section{Childhood trauma}

Childhood trauma was measured (at baseline at the Maastricht site; the other sites added this measure to the protocol at the follow-up measurement) with the Dutch version of the Childhood Trauma Questionnaire Short Form (CTQ-SF; Bernstein et al. 2003; Thombs et al. 2009), a 25-item self-report questionnaire rated on a five-point Likert scale with good internal consistency, reliability and validity (Thombs et al. 2009). The CTQ measures: physical abuse (bodily assaults on a child by an adult or older person that posed a risk of or resulted in injury); physical neglect (the failure of caretakers to provide for a child's basic physical needs, including food, shelter, clothing, safety and health care); sexual abuse (unwanted sexual contact or conduct between a child younger than 18 years of age and an adult or older person); emotional abuse (verbal assaults on a child's sense of worth or wellbeing or any humiliating or demeaning behavior directed toward a child by an adult or older person); and emotional neglect (the failure of caretakers to meet children's basic emotional and psychological needs, including love, belonging, nurturance and support), all occurring before the age of 17 .

For all analyses, three different trauma scales were used: total trauma (all five trauma types combined), abuse (emotional, physical and sexual abuse), and neglect (emotional and physical neglect). Each type of trauma was dichotomized into high trauma and low trauma, using the 80th percentile of trauma scores of controls, conforming with previous work (Heins et al. 2011) enabling us to present results based on comparable methods.

\section{Symptomatology}

The positive and negative subscales of the Positive and Negative Syndrome Scale (PANSS; Kay et al. 1987) were used to assess the severity of a variety of symptoms in the patient population at baseline and at the 3-year follow-up. The PANSS is a 30 -item interview originally consisting of three subscales [the positive scale (e.g. delusions/hallucinations), the negative scale (e.g. blunted affect, difficulty in abstract thinking) and a general psychopathology scale (e.g. depression, feelings of guilt)] and is scored on a seven-point scale ranging from 1 (absent) to 7 (very severe).

Siblings and controls were assessed at baseline and the 3-year follow-up with the Structured Interview for Schizotypy-Revised (SIS-R; Kendler et al. 1989; Vollema \& Ormel, 2000; Vollema \& Postma, 2002) to measure schizotypy. Guided by previous research 
(Hanssen et al. 2006), item scores were reduced a priori to two-dimensional scores, representing the means of positive schizotypy items (e.g. referential thinking, psychotic phenomena and derealization; range 0-2.7) and negative disorganized schizotypy items (e.g. social isolation and introversion; range 0-1.8).

Depressive symptoms in siblings and controls were assessed at baseline and the 3-year follow-up with the Community Assessment of Psychic Experiences (CAPE; www.cape42.homestead.com). The CAPE was developed for assessing self-reports of psychotic and depressive symptoms. For the purpose of this study, only the depression scale was used, as selfreports of psychotic experiences may yield high numbers of false positives (van Nierop et al. 2012). Each of the eight items was rated in terms of frequency, on a scale from 0 (never) to 3 (almost always).

Depressive symptoms in patients were assessed at the 3-year follow-up with the Calgary Depression Scale (CDS; Addington et al. 1990), an interview-based scale developed specifically for assessing depressive symptoms in patients with psychosis. Each of the nine items was rated in terms of severity, on a scale from 0 (absent) to 3 (severe). The CDS rather than the CAPE was used for the assessment of depression in the patients, as this measure was designed specifically for use in patients with a psychotic disorder.

\section{Cannabis use}

Cannabis use was assessed at baseline and the 3-year follow-up with the Composite International Diagnostic Interview (CIDI; WHO, 1990). Consistent with previous research in this sample (van Winkel et al. 2010), the cannabis pattern of use during the lifetime period of heaviest use was considered most informative and used for analysis: none (0), less than weekly (1), weekly (2) and daily (3).

\section{Procedure}

The study protocol was approved centrally by the Ethical Review Board of the University Medical Center Utrecht and subsequently by local review boards of each participating institute. All subjects gave written informed consent in accordance with the committee's guidelines. Assessments by trained research assistants took place at one of the participating regional psychosis departments or at the academic centers.

\section{Statistical analysis}

To determine the relationship between trauma and psychotic disorder, we used the assessments of trauma and diagnoses. Psychotic symptoms, schizotypy and depressive symptoms were assessed at baseline and follow-up, and analyses of these symptoms included both measurements, taking into account the withinperson level clustering of data. A priori confounders added to all analyses were age, gender and cannabis use (Matheson et al. 2011). All analyses were performed using Stata 11. Analyses were repeated including ethnicity (white, non-white), family history of depression and family history of psychosis as potential confounders (Morgan et al. 2010; van Winkel et al. 2013).

\section{Replication analyses}

To replicate earlier findings of an association between trauma and psychotic disorder or psychotic symptoms in the Maastricht sample (Heins et al. 2011), analyses were performed using the Amsterdam, Groningen and Utrecht samples.

\section{Between-group comparisons}

For the assessment of the association of total trauma, abuse or neglect with psychotic disorder, we used a case-control, case-sibling and sibling-control design. We conducted logistic regression analyses and accounted for dependent observations (clustering of families). In addition, a dose-response relationship between trauma and psychotic disorder was investigated in all groups by dividing the total trauma score of the controls into four quartiles and applying logistic regression analyses, accounting for dependence of observations by clustering for families.

\section{Childhood trauma and symptoms}

Multilevel regression analyses (XTMIXED command) were carried out to investigate the association between trauma and psychotic symptoms or schizotypy. Instead of analyzing the impact of trauma on each symptom category separately (which would only indicate whether trauma is significantly related to each symptom category), these multilevel models assess the differential impact of trauma on positive or negative symptoms within the same model. This approach is therefore preferable in the same sense that subgroup analyses in clinical trials should be conducted by testing proper interactions terms instead of analyzing subgroups separately (Pocock et al. 2002). The model (Supplementary Box 1) included a dummy variable to distinguish between the two symptom categories. Random effects were added to the multilevel model to account for clustering in families and within subjects. This analysis was performed separately for total trauma, abuse and neglect. 

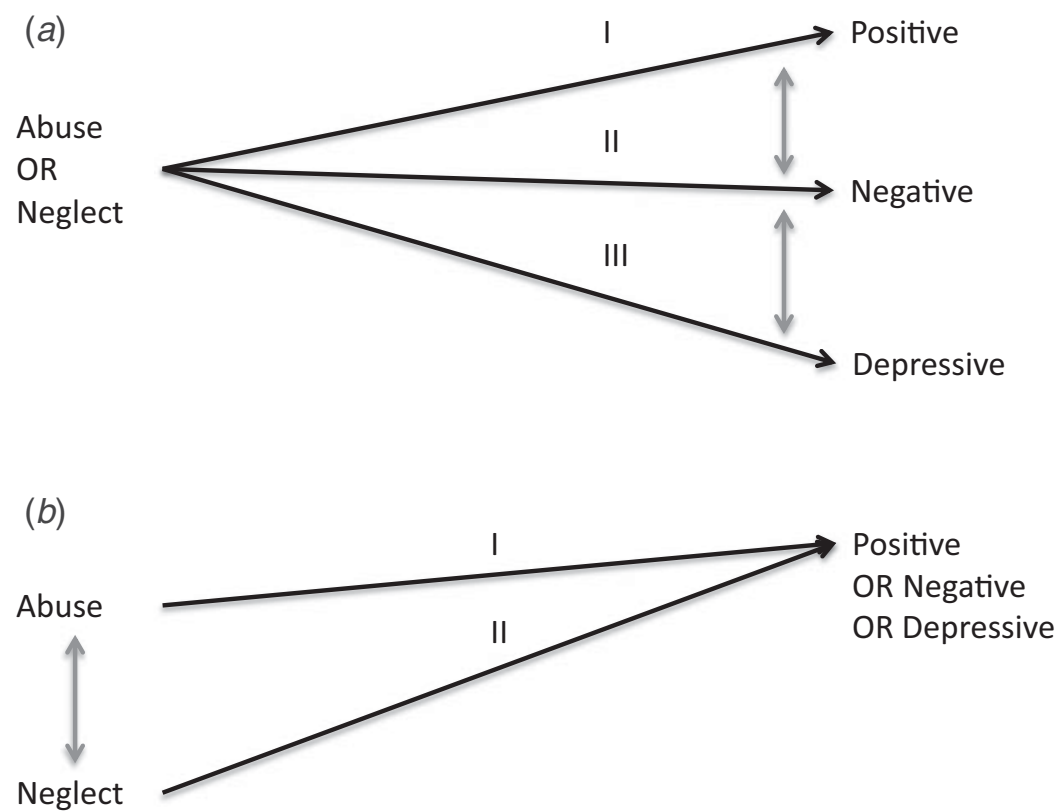

Fig. 1. (a) Specificity of trauma for symptoms. Testing the differences of the effect sizes of, e.g. abuse in association with each of the three symptom clusters, by comparing the B coefficients of arrows I, II and III. (b) Specificity of type of trauma for symptoms. Testing the differences of the effect sizes of, e.g. abuse and positive symptoms, versus neglect and positive symptoms, by comparing the $B$ coefficients of arrows I and II.

\section{Childhood trauma as a risk factor for developing psychosis or depression}

For the assessment of the differential association of trauma and relevant symptom clusters (positive and negative psychotic symptoms or schizotypy and depression, see Fig. 1a), multilevel regression analyses (XTMIXED command) were carried out, using the full sample (all sites). For this model, a second dummy was added to the previous model, allowing the estimation of the differential impact of trauma on the three symptom categories. Where available, both measurements were used in the analyses, while accounting for clustering within subjects and within families. This analysis was performed separately for total trauma, abuse and neglect.

\section{Type of trauma}

The analyses described above only allow for inferences on differential impact of trauma for symptoms (i.e. the differential impact of trauma on one symptom cluster versus another), and not for differences of influence of different types of trauma (i.e. influence of abuse versus neglect on symptom development, see Fig. 1b). We assessed differences of influence of abuse or neglect on positive, negative or depressive symptoms in all three groups, using the XTMIXED command. Both the baseline and first follow-up measurements were used.
Random effects were added to the multilevel model to account for clustering in families and within subjects. We performed separate analyses for each group and each symptom cluster as the dependent variable. Both abuse and neglect were added as independent variables. Post-hoc analyses were performed to assess differences in effect sizes of abuse or neglect using the LINCOM command.

\section{Influence of childhood trauma on course of symptoms}

To assess specificity (differential association between trauma and positive versus negative symptoms or schizotypy) and course of these symptoms, multilevel regression analyses were carried out using the full sample. All measurements of symptoms at baseline and follow-up were used in the analysis. For this model, additional two-way and three-way interaction terms were added to the previous model to estimate (a) the (differential) impact of trauma on the two symptom types at baseline, (b) the (differential) impact of trauma on the two symptom dimensions at follow-up, (c) the (differential) course of symptoms over time, and (d) how the (differential) course of symptoms over time was impacted by trauma (Supplementary Box 2). This analysis was performed separately for total trauma, abuse and neglect. 


\section{Results}

\section{Subject characteristics}

This study included 1119 patients, 1057 siblings and 589 controls at baseline (see Table 1 for characteristics). Of these, $75 \%(n=2074)$ were assessed at follow-up (controls: $78 \%, n=462$; siblings: $77 \%, n=810$; patients: $72 \%, n=802) ; 633$ of the patients completed the CTQ (baseline), the CDS (3-year follow-up) and the PANSS (baseline and follow-up). Baseline and followup data for the CTQ (baseline), the SIS-R and CAPE were available for 645 siblings and 407 controls. The other participants were excluded from the symptom analyses.

Patients who had to be excluded because of incomplete data did not differ significantly in terms of age or sex compared with patients who did participate on all measures. However, significantly more patients from a different ethnic background were excluded from analyses $(t=6.30, p<0.001)$. Controls excluded were significantly younger $(t=-3.03, p=0.003)$, more often male $(t=-1.98, p=0.048)$ and non-white $(t=2.69$, $p=0.007)$. The siblings who did not participate in all measures did not differ significantly in terms of age or sex but were more often non-white $(t=5.16, p<$ 0.001).

A description of the replication sample (recruited at the Amsterdam, Groningen and Utrecht sites) is shown in Table 1. Of these, 429 patients completed the CTQ (baseline), the CDS (3-year follow-up) and the PANSS (baseline and 3-year follow-up). In total, 497 siblings and 251 controls participated in all measurements. In analyses using the replication sample, only subjects who participated in all measurements were included.

In the replication sample, patients who were excluded from analyses did not differ significantly from participants in terms of age or sex. Patients who did not participate in all measures were, however, more often non-white than patients who did $(t=5.77, p<0.001)$. Controls who did not participate in all measurements were younger $(t=-2.38, p=0.018)$ and more often non-white than controls available for all measurements $(t=2.19, p=0.029)$. Siblings who did not participate in all measurements did not differ in age or sex; however, they were more often non-white $(t=5.15, p<0.001)$.

\section{Replication analyses}

Between-group comparisons

In the replication sample, total trauma, abuse and neglect were all associated with psychotic disorder in the case-control and case-sibling comparisons (Table 2), with evidence for positive dose-response relationships in both analyses (Supplementary
Table S1). Furthermore, siblings reported more childhood trauma compared with the controls (Table 2).

\section{Childhood trauma and symptoms}

In all three groups, total trauma, abuse and neglect were all associated with more severe positive and negative symptoms or schizotypy (Table 3). However, abuse was more strongly associated with positive than with negative symptoms or schizotypy whereas this differential impact was not found for neglect. These results remained robust after adding ethnicity, family history of depression and family history of psychosis as confounders.

\section{Childhood trauma as a risk factor for developing psychosis or depression}

In the patient sample (including the Maastricht sample), total trauma, abuse and neglect were associated with depressive symptoms (Table 4). As in the replication analysis, abuse showed a stronger association with positive than with negative symptoms; however, there were no differences in influence of abuse between positive and depressive symptoms. Abuse was more strongly associated with depression than with negative symptoms. Neglect did not show any specificity for symptoms; there were no differences in influence of neglect between all three symptom clusters.

In the sibling group (including the Maastricht sample), total trauma, abuse and neglect were also associated with depressive symptoms. Abuse showed the strongest association with depression, a weaker (yet significant) association with positive schizotypy, and the weakest (yet significant) association with negative schizotypy. Neglect showed a stronger association with depressive symptoms than with negative schizotypy. There was no evidence for a differential impact of neglect for positive versus negative schizotypy, or positive schizotypy versus depression (Table 4).

In the controls (including the Maastricht sample), abuse and neglect showed the strongest association with depression, a weaker (yet significant) association with positive schizotypy and the weakest (yet significant) association with negative schizotypy (Table 4). These results were not significantly altered after adding ethnicity, family history of depression or family history of psychosis as confounders.

\section{Type of childhood trauma}

Assessing the differential impact of abuse and neglect on symptoms, abuse showed a stronger association with positive symptoms than neglect, but only in the patient group (B 0.24, 95\% CI 0.09-0.40, $p=0.002$ ). In the sibling group, abuse showed a stronger association 
Table 1. Sociodemographic and clinical characteristics of patients, siblings and controls

\begin{tabular}{|c|c|c|c|c|c|c|}
\hline Full sample & \multicolumn{2}{|c|}{ Patients $(n=1119)$} & \multicolumn{2}{|c|}{ Siblings $(n=1057)$} & \multicolumn{2}{|c|}{ Controls $(n=589)$} \\
\hline Male gender, $n(\%)$ & \multicolumn{2}{|l|}{$852(76)$} & \multicolumn{2}{|l|}{$482(46)$} & \multicolumn{2}{|l|}{$269(46)$} \\
\hline Age at baseline (years), mean (s.D.) & \multicolumn{2}{|l|}{$27.6(8.0)$} & \multicolumn{2}{|l|}{$27.8(8.3)$} & \multicolumn{2}{|l|}{$30.4(10.6)$} \\
\hline Cannabis use ${ }^{\mathrm{a}}$, mean (S.D.) & \multicolumn{2}{|l|}{$1.21(1.35)$} & \multicolumn{2}{|l|}{$0.58(1.01)$} & \multicolumn{2}{|l|}{$0.38(0.82)$} \\
\hline \multicolumn{7}{|l|}{ GAF disability score, mean (S.D.) } \\
\hline Baseline & \multicolumn{2}{|l|}{$55.8(16.2)$} & \multicolumn{2}{|l|}{-} & \multicolumn{2}{|l|}{-} \\
\hline 3-year follow-up & \multicolumn{2}{|l|}{$60.1(16.4)$} & \multicolumn{2}{|l|}{-} & \multicolumn{2}{|l|}{-} \\
\hline \multicolumn{7}{|l|}{ GAF symptom score, mean (s.D.) } \\
\hline Baseline & \multicolumn{2}{|l|}{56.7 (16.2) } & \multicolumn{2}{|l|}{ - } & \multicolumn{2}{|l|}{ - } \\
\hline \multirow[t]{2}{*}{ 3-year follow-up } & \multicolumn{2}{|l|}{$59.4(16.3)$} & \multicolumn{2}{|l|}{-} & \multicolumn{2}{|l|}{-} \\
\hline & Low trauma & High trauma & Low trauma & High trauma & Low trauma & High trauma \\
\hline \multicolumn{7}{|c|}{ Positive symptoms/schizotypy ${ }^{\mathrm{b}}$, mean (s.D.) } \\
\hline Baseline & $1.65(0.67)$ & $2.01(0.91)$ & $0.37(0.39)$ & $0.57(0.48)$ & $0.31(0.32)$ & $0.53(0.48)$ \\
\hline 3-year follow-up & $1.47(0.59)$ & $1.70(0.69)$ & $0.30(0.29)$ & $0.53(0.38)$ & $0.25(0.27)$ & $0.41(0.30)$ \\
\hline \multicolumn{7}{|c|}{ Negative symptoms/schizotypy ${ }^{c}$, mean (S.D.) } \\
\hline Baseline & $1.81(0.80)$ & $2.01(0.94)$ & $0.25(0.23)$ & $0.34(0.29)$ & $0.24(0.22)$ & $0.31(0.26)$ \\
\hline 3-year follow-up & $1.60(0.64)$ & $1.72(0.79)$ & $0.28(0.23)$ & $0.42(0.29)$ & $0.25(0.21)$ & $0.31(0.24)$ \\
\hline \multicolumn{7}{|l|}{ Depressive symptoms ${ }^{\mathrm{d}}$, mean (s.D.) } \\
\hline Baseline & - & - & $0.58(0.36)$ & $0.81(0.44)$ & $0.53(0.29)$ & $0.84(0.45)$ \\
\hline 3-year follow-up & $1.40(0.60)$ & $1.58(0.74)$ & $0.45(0.36)$ & $0.69(0.46)$ & $0.39(0.30)$ & $0.62(0.46)$ \\
\hline \multicolumn{7}{|c|}{ Trauma scores dichotomized by 80th percentile of control scores, $n$ high trauma (\%) } \\
\hline Total trauma & \multicolumn{2}{|c|}{$336(44)$} & $202(25)$ & & $94(19)$ & \\
\hline Abuse & $336(44)$ & & $214(26)$ & & $101(20)$ & \\
\hline Neglect & $311(41)$ & & $203(25)$ & & $95(19)$ & \\
\hline Continuous trauma scores, mean (s.l & & & & & & \\
\hline Total trauma score & $1.61(0.50)$ & & $1.41(0.41)$ & & $1.34(0.35)$ & \\
\hline Abuse score & $1.44(0.52)$ & & $1.26(0.40)$ & & $1.22(0.34)$ & \\
\hline Neglect score & $1.86(0.63)$ & & $1.64(0.55)$ & & $1.53(0.49)$ & \\
\hline
\end{tabular}




\begin{tabular}{|c|c|c|c|c|c|c|}
\hline Replication sample ${ }^{\mathrm{e}}$ & \multicolumn{2}{|c|}{ Patients $(n=813)$} & \multicolumn{2}{|c|}{ Siblings $(n=768)$} & \multicolumn{2}{|c|}{ Controls $(n=345)$} \\
\hline Male gender, $n(\%)$ & $634(78)$ & & $353(46)$ & & $188(54)$ & \\
\hline Age at baseline (years), mean (S.D.) & $27.5(7.8)$ & & $27.9(8.1)$ & & $29.5(9.9)$ & \\
\hline \multirow[t]{2}{*}{ Cannabis use ${ }^{\mathrm{a}}$, mean (S.D.) } & $1.25(1.35)$ & & $0.56(1.0)$ & & $0.46(0.90)$ & \\
\hline & Low trauma & High trauma & Low trauma & High trauma & Low trauma & High trauma \\
\hline \multicolumn{7}{|c|}{ Positive symptoms/schizotypy ${ }^{\text {, }}$, mean (S.D.) } \\
\hline Baseline & $1.66(0.65)$ & $2.05(0.84)$ & $0.23(0.29)$ & $0.40(0.36)$ & $0.17(0.22)$ & $0.30(0.30)$ \\
\hline 3-year follow-up & $1.45(0.53)$ & $1.81(0.70)$ & $0.23(0.27)$ & $0.41(0.35)$ & $0.22(0.26)$ & $0.39(0.30)$ \\
\hline \multicolumn{7}{|c|}{ Negative symptoms/schizotypyc, mean (S.D.) } \\
\hline Baseline & $1.90(0.73)$ & $2.25(0.88)$ & $0.22(0.24)$ & $0.30(0.27)$ & $0.18(0.19)$ & $0.27(0.21)$ \\
\hline 3-year follow-up & $1.64(0.61)$ & $1.89(0.84)$ & $0.24(0.24)$ & $0.39(0.28)$ & $0.23(0.22)$ & $0.36(0.29)$ \\
\hline \multicolumn{7}{|c|}{ Trauma scores dichotomized by 80th percentile of control scores, $n$ high trauma (\%) } \\
\hline Total trauma & $196(41)$ & & $125(23)$ & & $47(18)$ & \\
\hline Abuse & $196(41)$ & & $145(26)$ & & $49(19)$ & \\
\hline Neglect & $184(39)$ & & $123(22)$ & & $48(18)$ & \\
\hline \multicolumn{7}{|l|}{ Continuous trauma scores, mean (S.D.) } \\
\hline Total trauma score & $1.58(0.48)$ & & $1.40(0.39)$ & & $1.33(0.33)$ & \\
\hline Abuse score & $1.41(0.50)$ & & $1.26(0.37)$ & & $1.20(0.31)$ & \\
\hline Neglect score & $1.83(0.61)$ & & $1.62(0.53)$ & & $1.52(0.46)$ & \\
\hline
\end{tabular}

GAF, Global Assessment of Functioning; s.D., standard deviation.

${ }^{a}$ Cannabis use assessed as frequency of use in the most intensive lifetime period on a scale from 0 (none) to 3 (daily).

${ }^{b}$ Positive symptoms measured with the Positive and Negative Syndrome Scale (PANSS) in patients, positive schizotypy measured with the Structured Interview for Schizotypy Revised (SIS-R) in siblings and controls.

${ }^{\mathrm{c}}$ Negative symptoms measured with the PANSS in patients, negative schizotypy measured with the SIS-R in siblings and controls.

${ }^{\mathrm{d}}$ Depressive symptoms measured with the Calgary Depression Scale (CDS) at the 3-year follow-up only in patients, depressive symptoms measured with the Community Assessment of Psychic Experiences (CAPE) at baseline and follow-up in siblings and controls.

${ }^{\mathrm{e}}$ Replication sample includes participants from the Amsterdam, Groningen and Utrecht sites only. 
Table 2. Association of all types of trauma and psychotic disorder: case-control, case-sibling and sibling-control comparisons

\begin{tabular}{|c|c|c|c|c|c|c|}
\hline & \multicolumn{2}{|l|}{ Case $v$. control } & \multicolumn{2}{|l|}{ Case $v$. sibling } & \multicolumn{2}{|l|}{ Sibling $v$. control } \\
\hline & OR (95\% CI) & $p$ value & OR $(95 \%$ CI) & $p$ value & OR $(95 \%$ CI $)$ & $p$ value \\
\hline Total trauma & $3.11(2.06-4.70)$ & $<0.001$ & $2.57(1.92-3.43)$ & $<0.001$ & $1.28(0.86-1.91)$ & 0.219 \\
\hline Abuse & $3.24(2.16-4.86)$ & $<0.001$ & $2.23(1.65-3.00)$ & $<0.001$ & $1.51(1.03-2.21)$ & 0.035 \\
\hline Neglect & $2.56(1.71-3.83)$ & $<0.001$ & $2.15(1.61-2.87)$ & $<0.001$ & $1.32(0.90-1.95)$ & 0.158 \\
\hline
\end{tabular}

OR, Odds ratio; $\mathrm{CI}$, confidence interval.

A priori corrected for age, gender, and cannabis use.

Table 3. Associations of trauma and PANSS symptoms (patients) or SIS-R schizotypy (siblings and controls)

\begin{tabular}{|c|c|c|c|c|}
\hline Type of childhood trauma and group & $B$ coefficient $(95 \% \mathrm{CI})$ & $p$ value & Comparison of effect sizes ${ }^{a}$ & $p$ value \\
\hline \multicolumn{5}{|l|}{ Total trauma } \\
\hline \multicolumn{5}{|l|}{ Patients } \\
\hline Positive symptoms & $0.35(0.24-0.45)$ & $<0.001$ & \multirow[t]{2}{*}{$-0.07(-0.18$ to 0.04$)$} & \multirow[t]{2}{*}{0.202} \\
\hline Negative symptoms & $0.27(0.17-0.38)$ & $<0.001$ & & \\
\hline \multicolumn{5}{|l|}{ Siblings } \\
\hline Positive schizotypy & $0.16(0.11-0.21)$ & $<0.001$ & \multirow[t]{2}{*}{$-0.06(-0.10$ to -0.02$)$} & \multirow[t]{2}{*}{0.004} \\
\hline Negative schizotypy & $0.10(0.05-0.15)$ & $<0.001$ & & \\
\hline \multicolumn{5}{|l|}{ Controls } \\
\hline Positive schizotypy & $0.16(0.10-0.22)$ & $<0.001$ & \multirow[t]{2}{*}{$-0.04(-0.11$ to 0.02$)$} & \multirow[t]{2}{*}{0.181} \\
\hline Negative schizotypy & $0.11(0.05-0.17)$ & $<0.001$ & & \\
\hline \multicolumn{5}{|l|}{ Abuse } \\
\hline \multicolumn{5}{|l|}{ Patients } \\
\hline Positive symptoms & $0.36(0.25-0.47)$ & $<0.001$ & \multirow[t]{2}{*}{$-0.19(-0.30$ to -0.08$)$} & \multirow[t]{2}{*}{0.001} \\
\hline Negative symptoms & $0.17(0.06-0.28)$ & 0.002 & & \\
\hline \multicolumn{5}{|l|}{ Siblings } \\
\hline Positive schizotypy & $0.15(0.10-0.19)$ & $<0.001$ & \multirow[t]{2}{*}{$-0.04(-0.08$ to -0.003$)$} & \multirow[t]{2}{*}{0.035} \\
\hline Negative schizotypy & $0.11(0.06-0.15)$ & $<0.001$ & & \\
\hline \multicolumn{5}{|l|}{ Controls } \\
\hline Positive schizotypy & $0.18(0.12-0.24)$ & $<0.001$ & \multirow{2}{*}{$-0.08(-0.14$ to -0.02$)$} & \multirow[t]{2}{*}{0.012} \\
\hline Negative schizotypy & $0.10(0.04-0.16)$ & 0.001 & & \\
\hline \multicolumn{5}{|l|}{ Neglect } \\
\hline \multicolumn{5}{|l|}{ Patients } \\
\hline Positive symptoms & $0.25(0.14-0.35)$ & $<0.001$ & \multirow[t]{2}{*}{$0.003(-0.11$ to 0.12$)$} & \multirow[t]{2}{*}{0.952} \\
\hline Negative symptoms & $0.25(0.14-0.36)$ & $<0.001$ & & \\
\hline \multicolumn{5}{|l|}{ Siblings } \\
\hline Positive schizotypy & $0.11(0.07-0.16)$ & $<0.001$ & \multirow[t]{2}{*}{-0.0003 ( -0.04 to 0.04$)$} & \multirow[t]{2}{*}{0.991} \\
\hline Negative schizotypy & $0.11(0.07-0.16)$ & $<0.001$ & & \\
\hline \multicolumn{5}{|l|}{ Controls } \\
\hline Positive schizotypy & $0.16(0.10-0.21)$ & $<0.001$ & \multirow[t]{2}{*}{$-0.03(-0.10$ to 0.03$)$} & \multirow[t]{2}{*}{0.277} \\
\hline Negative schizotypy & $0.12(0.06-0.18)$ & $<0.001$ & & \\
\hline
\end{tabular}

PANSS, Positive and Negative Syndrome Scale; SIS-R, Structured Interview for Schizotypy - Revised; CI, confidence interval.

A priori corrected for age, gender and cannabis use.

${ }^{a}$ Negative values indicates stronger association of trauma with positive symptoms. Positive values indicate stronger association of trauma with negative symptoms.

with depression than neglect (B $0.12,95 \%$ CI $0.03-0.22$, $p=0.012)$. In controls, there was no differential effect of trauma type on any symptom domain. Similar results were obtained after adding ethnicity, family history of depression and family history of psychosis as confounders. 
Table 4. Associations of trauma and depressive symptoms, PANSS symptoms (patients) or SIS-R schizotypy (siblings and controls)

\begin{tabular}{|c|c|c|c|}
\hline \multirow{2}{*}{$\begin{array}{l}\text { Type of childhood } \\
\text { trauma and group }\end{array}$} & \multirow[b]{2}{*}{ B coefficient $(95 \% \mathrm{CI})$} & \multicolumn{2}{|l|}{ Comparison of effect sizes ${ }^{a}$} \\
\hline & & versus negative (symptoms/schizotypy) & versus depressive symptoms \\
\hline \multicolumn{4}{|l|}{ Total trauma } \\
\hline \multicolumn{4}{|l|}{ Patients } \\
\hline Positive symptoms & $0.25^{* * *}(0.15$ to 0.35$)$ & \multirow{3}{*}{$-0.10(-0.22$ to 0.02$)$} & $-0.06(-0.19$ to 0.06$)$ \\
\hline Negative symptoms & $0.14^{* *}(0.04$ to 0.24$)$ & & $-0.04(-0.16$ to 0.08$)$ \\
\hline Depressive symptoms & $0.18^{* * *}(0.08$ to 0.28$)$ & & \\
\hline \multicolumn{4}{|l|}{ Siblings } \\
\hline Positive schizotypy & $0.18^{* * *}(0.13$ to 0.22$)$ & \multirow[t]{3}{*}{$-0.09^{* * *}(-0.13$ to -0.04$)$} & $0.04(-0.01$ to 0.08$)$ \\
\hline Negative schizotypy & $0.09^{* * *}(0.04$ to 0.14$)$ & & $-0.13^{* * *}(-0.17$ to -0.08$)$ \\
\hline Depressive symptoms & $0.22^{* * *}(0.17$ to 0.26$)$ & & \\
\hline \multicolumn{4}{|l|}{ Controls } \\
\hline Positive schizotypy & $0.18^{* * *}(0.12$ to 0.23$)$ & \multirow[t]{3}{*}{$-0.10^{* *}(-0.16$ to -0.04$)$} & $0.09^{* *}(0.04$ to 0.15$)$ \\
\hline Negative schizotypy & $0.08^{* *}(0.02$ to 0.13$)$ & & $-0.19^{* * *}(-0.25$ to -0.13$)$ \\
\hline Depressive symptoms & $0.27^{* * *}(0.21$ to 0.32$)$ & & \\
\hline \multicolumn{4}{|l|}{ Abuse } \\
\hline \multicolumn{4}{|l|}{ Patients } \\
\hline Positive symptoms & $0.30^{* * *}(0.19$ to 0.39$)$ & \multirow[t]{3}{*}{$-0.24^{* * *}(-0.36$ to -0.12$)$} & $-0.07(-0.19$ to 0.06$)$ \\
\hline Negative symptoms & $0.05(-0.05$ to 0.15$)$ & & $-0.18^{* *}(-0.30$ to -0.05$)$ \\
\hline Depressive symptoms & $0.23^{* * *}(0.12$ to 0.33$)$ & & \\
\hline \multicolumn{4}{|l|}{ Siblings } \\
\hline Positive schizotypy & $0.17^{* * *}(0.12$ to 0.20$)$ & \multirow[t]{3}{*}{$-0.08^{* *}(-0.12$ to -0.03$)$} & $0.09^{* *}(0.04$ to 0.13$)$ \\
\hline Negative schizotypy & $0.09^{* * *}(0.05$ to 0.13$)$ & & $-0.16^{* * *}(-0.21$ to -0.12$)$ \\
\hline Depressive symptoms & $0.25^{* * *}(0.21$ to 0.30$)$ & & \\
\hline \multicolumn{4}{|l|}{ Controls } \\
\hline Positive schizotypy & $0.18^{* * *}(0.12$ to 0.23$)$ & \multirow[t]{3}{*}{$-0.10^{* * *}(-0.16$ to -0.05$)$} & $0.06^{*}(0.004$ to 0.12$)$ \\
\hline Negative schizotypy & $0.07^{* *}(0.02$ to 0.13$)$ & & $-0.16^{* * *}(-0.22$ to -0.11$)$ \\
\hline Depressive symptoms & $0.24^{* * *}(0.18$ to 0.29$)$ & & \\
\hline \multicolumn{4}{|l|}{ Neglect } \\
\hline \multicolumn{4}{|l|}{ Patients } \\
\hline Positive symptoms & $0.16^{* *}(0.06$ to 0.26$)$ & \multirow[t]{3}{*}{$0.04(-0.08$ to 0.16$)$} & $-0.01(-0.14$ to 0.11$)$ \\
\hline Negative symptoms & $0.20^{* * *}(0.10$ to 0.30$)$ & & $0.05(-0.07$ to 0.17$)$ \\
\hline Depressive symptoms & $0.15^{* *}(0.05$ to 0.25$)$ & & \\
\hline \multicolumn{4}{|l|}{ Siblings } \\
\hline Positive schizotypy & $0.13^{* * *}(0.09$ to 0.18$)$ & \multirow[t]{3}{*}{-0.03 ( -0.08 to 0.01$)$} & $0.04(-0.01$ to 0.08$)$ \\
\hline Negative schizotypy & $0.10^{* * *}(0.06$ to 0.15$)$ & & $-0.07^{* *}(-0.11$ to -0.02$)$ \\
\hline Depressive symptoms & $0.17^{* * *}(0.13$ to 0.22$)$ & & \\
\hline \multicolumn{4}{|l|}{ Controls } \\
\hline Positive schizotypy & $0.17^{* * *}(0.11$ to 0.22$)$ & \multirow[t]{3}{*}{$-0.08^{* *}(-0.13$ to -0.02$)$} & $0.07^{*}$ (0.01 to 0.12$)$ \\
\hline Negative schizotypy & $0.09^{* *}(0.03$ to 0.14$)$ & & $-0.14^{* * *}(-0.20$ to -0.09$)$ \\
\hline Depressive symptoms & $0.23^{* * *}(0.18$ to 0.29$)$ & & \\
\hline
\end{tabular}

\footnotetext{
${ }^{a}$ Comparison of effect sizes. Left column: positive versus negative symptoms/schizotypy. Negative values indicate stronger associations of trauma and positive symptoms. Right column, upper line: positive symptoms/schizotypy versus depressive symptoms. Negative values indicate stronger associations of trauma and positive symptoms. Right column, lower line: negative symptoms/schizotypy versus depressive symptoms. Negative values indicate stronger associations of trauma and depressive symptoms.

A priori corrected for age, gender and cannabis.

${ }^{*} p<0.05,{ }^{* *} p<0.01,{ }^{* * *} p<0.001$.
}

\section{Influence of childhood trauma on course of symptoms}

Neither abuse nor neglect were significantly associated with a differential course over the 3-year follow-up period of positive, negative or depressive symptom domains in the three groups. That is, the course of symptom domains was similar in traumatized versus non-traumatized individuals (Supplementary 
Table S2). Adding ethnicity, family history of depression or family history of psychosis did not influence these results significantly.

\section{Discussion}

\section{Replication analyses}

The current study adds evidence to the notion that childhood trauma is associated with (subthreshold) psychosis. Evidence for a dose-response relationship was found for case-control, case-sibling and siblingcontrol comparisons, holding that more childhood trauma is associated with more severe psychopathology. These findings are in keeping with the results of Heins et al. (2011), and are now replicated by making use of a substantially larger, independent sample of patients, siblings and control subjects.

In line with recent literature we found that people who experienced abuse and neglect in their childhood were more vulnerable to develop both (subthreshold) positive and negative symptoms than people who did not experience childhood trauma (Ross et al. 1994; Janssen et al. 2004; Heins et al. 2011). Moreover, our results indicate that childhood abuse or neglect may differentially impact on symptomatology. Although associations with abuse were more pronounced for positive symptoms, associations with neglect were comparable for both symptom domains.

\section{Childhood trauma as a risk factor for developing psychosis or depression}

Our results do not support the hypothesis that childhood trauma specifically increases the chance of developing psychotic symptoms compared to depressive symptoms, not even in subjects with a (genetic risk of) psychosis. In patients with a history of childhood trauma, the risk of reporting more severe psychotic or depressive symptoms was comparable in siblings and controls but stronger associations were found between trauma and depressive symptomatology. These findings indicate that childhood trauma may contribute to a shared vulnerability for psychotic and depressive symptoms.

There are several theories that could explain this shared vulnerability. One of these theories underscores the role of negative beliefs about self and others in the relationship between childhood trauma and psychopathology. In this theory, it is argued that the experience of childhood trauma may heighten the change of developing negative schemas of the self and the world (Garety et al. 2001). Although negative schemata of the self and others may arguably cause depressive symptoms, Garety et al. (2001) showed that they could eventually also contribute to the development of psychotic symptoms. It may be that childhood abuse or neglect in childhood increases hypervigilance to hostile cues from people in their environment, a mechanism that could also feed paranoid ideation and ideas of reference (Garety et al. 2001; Morrison et al. 2003; Bentall \& Fernyhough, 2008; Read \& Gumley, 2008). A second theory suggests that traumatic events alter brain systems (Perry et al. 2008), giving rise to a variety of psychiatric disorders (Heim \& Nemeroff, 2001; Kapur, 2003; Heim et al. 2008). For example, trauma during childhood could lead to a dysregulation of the hypothalamic-pituitary-adrenal (HPA) axis (Walker \& Diforio, 1997), possibly caused by alterations in the cortisol feedback loop (Binder et al. 2008; Collip et al. 2013), that may result in the emergence of both psychotic and/or depressive symptoms (Kapur, 2003; Heim et al. 2008).

\section{Type of childhood trauma}

In agreement with previous work, associations between childhood abuse and symptoms were stronger than between symptoms and neglect. In addition, although associations with abuse were more pronounced for positive symptoms, associations with neglect were comparable for both symptom domains. This divergence may suggest that abuse and neglect impact differently on neurodevelopmental, social and emotional development (Glaser, 2000; Perry et al. 2008). Abuse, in particular, is considered to be highly stressful and is assumed to alter brain systems that are involved in mediating the stress response and that have mostly been related to the development of positive psychotic symptoms (Kapur, 2003). A different pathway has been proposed for people with a history of neglect. This hypothesized pathway is based on the encountered association between a history of deprivation from stimulating experiences and several cognitive and psychosocial deficits in children (Colvert et al. 2008), deficits that in turn have been found to be associated with higher levels of both positive and negative symptoms (Rabinowitz et al. 2002; Addington et al. 2003).

\section{Course of symptoms}

Our results are in agreement with general population studies suggesting that childhood trauma not only predicts the development of psychotic symptoms but also impacts on the persistency of symptoms (De Loore et al. 2007; Schreier et al. 2009; Arseneault et al. 2011; Mackie et al. 2011; Kelleher et al. 2013). In our sample, individuals with childhood trauma reported higher levels of symptoms both at baseline and at the 3-year follow-up in comparison to individuals without childhood trauma. This finding indicates not only that the 
experience of childhood trauma creates a vulnerability to develop more severe (subthreshold) psychotic symptoms but also that these heightened symptom levels are present over time. As childhood trauma has been suggested to create enduring cognitive biases and longlasting alterations in stress systems associated with the development of psychotic symptoms (Garety et al. 2001; Kapur, 2003; Bentall \& Fernyhough, 2008; Binder et al. 2008; Perry et al. 2008; Collip et al. 2013), we might expect that, in individuals with a history of childhood trauma, the severity of symptoms would have been constant or increasing over time. However, we did not find childhood trauma to be related to a differential course of symptom domains (that is, although patients with childhood trauma have higher symptom levels at baseline and follow-up, symptoms in the trauma group decreased to a similar extent compared to the nontrauma group). This finding tentatively suggests that having experienced a traumatic event in childhood does not necessarily indicate a deteriorating outcome compared to those who did not experience a traumatic event in childhood, at least not on a symptom level.

\section{Methodological issues}

Some methodological limitations need to be taken into consideration when interpreting these findings. First, childhood trauma was measured by using a retrospective, self-report questionnaire, which increases the chance of report(ing) biases and recall biases. However, studies on retrospective self-report measures of childhood trauma have shown considerable reliability (Fisher et al. 2011). Moreover, the instrument we used to measure childhood trauma is well-validated and was found to be a reliable measurement in previous studies (Bernstein et al. 2003; Thombs et al. 2009).

Second, the study lacks detailed information about the childhood trauma experienced, such as timing, age of occurrence, subject's relationship to the perpetrator, severity and duration of trauma. Morgan \& Fisher (2007) argued that, when investigating trauma, timing, (perceived) severity and duration of trauma should be taken into account because they are likely to influence the association with psychotic symptomatology. This is considered an important issue for further research on childhood trauma.

Third, for the measurement of depressive symptoms in different groups of participants, different instruments were used. However, the CDS was specifically developed for the reliable and valid assessment of depression in schizophrenia patients, in contrast to the CAPE, which was developed for assessing positive, negative and depressive symptoms in non-clinical groups. In particular, the CAPE is less able to differentiate between negative and depressive symptoms.
Therefore, we preferred to use the CDS for our within-group analyses assessing the different influence of childhood trauma on positive, negative and depressive symptoms. However, as a limitation we cannot make inferences about the differential influence of childhood trauma on symptomatology between these groups.

Fourth, although we made an effort to include a representative prevalence sample of patients with psychosis and their siblings in the present study, we cannot fully exclude the possibility of selection bias. Unfortunately, we have no systematic records of reasons for refusal of all eligible cases that were approached but refused participation. This should be taken into account when considering the generalizability of our findings. Moreover, we were not able to prevent drop-out of participants over time. We found that participants who were lost during follow-up were more often non-white compared with participants completing both measurements. Controls who did participate on both measurements were slightly older than controls not participating on both measurements. We have investigated whether ethnicity (white/non-white), gender and sex were influential confounders for our analyses, and found that they were not. Therefore, we do not consider that the drop-out of participants over time had much impact on our results.

The major strength of this study is that we were able to take into account the association with the course of symptom domains and the association with depression in subjects with variation in psychosis vulnerability. By using statistical techniques, we were able to assess the influence of trauma on several different, yet often co-occurring, symptoms.

In conclusion, this study strengthens and extends the evidence for a robust association between childhood trauma and psychotic symptoms across different levels of severity. However, we found no support for the hypothesis that childhood trauma specifically increases the chance of developing psychotic symptoms compared to depressive symptoms. Moreover, although patients with childhood trauma had higher symptom levels at baseline and at the 3-year follow-up, childhood trauma was not associated with a differential course of symptoms.

\section{Supplementary material}

For supplementary material accompanying this paper visit http://dx.doi.org/10.1017/S0033291714001561.

\section{Acknowledgments}

We are grateful for the generosity of time and effort by the families who make the GROUP project possible. 
This work was supported by the Geestkracht program of the Dutch Health Research Council (ZON-MW, grant no. 10-000-1002) and matching funds from participating universities and mental health care organizations (Site Amsterdam: Academic Psychiatric Center AMC, Ingeest, Arkin, Dijk en Duin, Rivierduinen, Erasmus MC, GGZ Noord Holland Noord; Site Utrecht: University Medical Center Utrecht, Altrecht, Symfora, Meerkanten, Riagg Amersfoort, Delta; Site Groningen: University Medical Center Groningen, Lentis, GGZ Friesland, GGZ Drenthe, Dimence, Mediant, GGZ De Grote Rivieren, Parnassia Psycho-Medical Center; Site Maastricht: Maastricht University Medical Center, GGZ Eindhoven, GGZ Midden-Brabant, GGZ Oost-Brabant, GGZ Noord-Midden Limburg, Mondriaan Zorggroep, Prins Clauscentrum Sittard, RIAGG Roermond, Universitair Centrum Sint-Jozef Kortenberg, CAPRI University of Antwerp, PC Ziekeren Sint-Truiden, PZ Sancta Maria Sint-Truiden, GGZ Overpelt, OPZ Rekem). The analyses were supported by unrestricted grants from Jansen-Cilag, Eli Lilly and Company, Astra-Zeneca and Lundbeck. The research leading to these results has received funding from the European Community's Seventh Framework Program under grant agreement HEALTH-F2-2009-241909 (Project EU-GEI).

\section{Declaration of Interest}

None.

\section{References}

Addington D, Addington J, Schissel B (1990). A depression rating scale for schizophrenics. Schizophrenia Research 3, 247-251.

Addington J, van Mastrigt S, Addington D (2003). Patterns of premorbid functioning in first-episode psychosis: initial presentation. Schizophrenia Research 62, 23-30.

Andreasen NC (1982). Negative symptoms in schizophrenia. Definition and reliability. Archives of General Psychiatry 39, 784-788.

Andreasen NC (1984). Scale for the Assessment of Positive Symptoms. University of Iowa: Iowa City, IA.

Andreasen NC, Flaum M, Arndt S (1992). The Comprehensive Assessment of Symptoms and History (CASH). An instrument for assessing diagnosis and psychopathology. Archives of General Psychiatry 49, 615-623. APA (2000). Diagnostic and Statistical Manual of Mental Disorders, Fourth Edition, Text Revision. DSM-IV-TR. American Psychiatric Association: Washington, DC.

Arseneault L, Cannon M, Fisher HL, Polanczyk G, Moffitt TE, Caspi A (2011). Childhood trauma and children's emerging psychotic symptoms: a genetically sensitive longitudinal cohort study. American Journal of Psychiatry 168, 65-72.

Bentall RP, Fernyhough C (2008). Social predictors of psychotic experiences: specificity and psychological mechanisms. Schizophrenia Bulletin 34, 1012-1020.

Bentall RP, Wickham S, Shevlin M, Varese F (2012). Do specific early-life adversities lead to specific symptoms of psychosis? A study from the 2007 the Adult Psychiatric Morbidity Survey. Schizophrenia Bulletin 38, 734-740.

Bernstein DP, Stein JA, Newcomb MD, Walker E, Pogge D, Ahluvalia T, Stokes J, Handelsman L, Medrano M, Desmond D (2003). Development and validation of a brief screening version of the Childhood Trauma Questionnaire. Child Abuse and Neglect 27, 169-190.

Binder EB, Bradley RG, Liu W, Epstein MP, Deveau TC, Mercer KB, Tang Y, Gillespie CF, Heim CM, Nemeroff CB (2008). Association of FKBP5 polymorphisms and childhood abuse with risk of posttraumatic stress disorder symptoms in adults. Journal of the American Medical Association 299, 1291-1305.

Collip D, Myin-Germeys I, Wichers M, Jacobs N, Derom C, Thiery E, Lataster T, Simons C, Delespaul P, Marcelis M, van Os J, van Winkel R (2013). FKBP5 as a possible moderator of the psychosis-inducing effects of childhood trauma. British Journal of Psychiatry 202, 261-268.

Colvert E, Rutter M, Kreppner J, Beckett C, Castle J, Groothues C, Hawkins A, Stevens S, Sonuga-Barke EJ (2008). Do theory of mind and executive function deficits underlie the adverse outcomes associated with profound early deprivation? Findings from the English and Romanian adoptees study. Journal of Abnormal Child Psychology 36, 1057-1068.

Conus P, Cotton S, Schimmelmann BG, McGorry PD, Lambert M (2010). Pretreatment and outcome correlates of sexual and physical trauma in an epidemiological cohort of first-episode psychosis patients. Schizophrenia Bulletin 36, 1105-1114.

Cougnard A, Marcelis M, Myin-Germeys I, de Graaf R, Vollebergh W, Krabbendam L, Lieb R, Wittchen HU, Henquet CEC, Spauwen J (2007). Does normal developmental expression of psychosis combine with environmental risk to cause persistence of psychosis? A psychosis proneness-persistence model. Psychological Medicine 37, 513-528.

De Loore E, Drukker M, Gunther N, Feron F, Deboutte D, Sabbe B, Mengelers R, van Os J, Myin-Germeys I (2007) Childhood negative experiences and subclinical psychosis in adolescence: a longitudinal general population study. Early Intervention in Psychiatry 1, 201-207.

Fisher HL, Craig TK, Fearon P, Morgan K, Dazzan P, Lappin J, Hutchinson G, Doody GA, Jones PB, McGuffin P (2011). Reliability and comparability of psychosis patients' retrospective reports of childhood abuse. Schizophrenia Bulletin 37, 546-553.

Garety P, Kuipers E, Fowler D, Freeman D, Bebbington P (2001). A cognitive model of the positive symptoms of psychosis. Psychological Medicine 31, 189-195.

Glaser D (2000). Child abuse and neglect and the brain -a review. Journal of Child Psychology and Psychiatry 41, 97-116. 
Greenfield SF, Strakowski SM, Tohen M, Batson SC, Kolbrener ML (1994). Childhood abuse in first-episode psychosis. British Journal of Psychiatry 164, 831-834.

Hanssen M, Krabbendam L, Vollema M, Delespaul P, van Os J (2006). Evidence for instrument and family-specific variation of subclinical psychosis dimensions in the general population. Journal of Abnormal Psychology 115, 5-14.

Heim C, Nemeroff CB (2001). The role of childhood trauma in the neurobiology of mood and anxiety disorders: preclinical and clinical studies. Biological Psychiatry 49, 1023-1039.

Heim C, Newport DJ, Mletzko T, Miller AH, Nemeroff CB (2008). The link between childhood trauma and depression: insights from HPA axis studies in humans.

Psychoneuroendocrinology 33, 693-710.

Heins M, Simons C, Lataster T, Pfeifer S, Versmissen D, Lardinois M, Marcelis M, Delespaul P, Krabbendam L, van Os J, Myin-Germeys I (2011). Childhood trauma and psychosis: a case-control and case-sibling comparison across different levels of genetic liability, psychopathology, and type of trauma. American Journal of Psychiatry 168, 1286-1294.

Hovens JGFM, Giltay EJ, Wiersma JE, Spinhoven P, Penninx BWJH, Zitman FG (2012). Impact of childhood life events and trauma on the course of depressive and anxiety disorders. Acta Psychiatrica Scandinavica 126, 198-207.

Hox JJ (2010). Multilevel Analysis: Techniques and Applications, 2nd edn. Routledge: New York, NY.

Janssen I, Krabbendam L, Bak M, Hanssen M, Vollebergh W, de Graaf R, van Os J (2004). Childhood abuse as a risk factor for psychotic experiences. Acta Psychiatrica Scandinavica 109, 38-45.

Kapur S (2003). Psychosis as a state of aberrant salience: a framework linking biology, phenomenology, and pharmacology in schizophrenia. American Journal of Psychiatry 160, 13-23.

Kay SR, Fiszbein A, Opfer LA (1987). The positive and negative syndrome scale (PANSS) for schizophrenia. Schizophrenia Bulletin 13, 261-276.

Kelleher I, Keeley H, Corcoran P, Ramsay H, Wasserman C, Carli V, Sarchiapone M, Hoven C, Wasserman D, Cannon M (2013). Childhood trauma and psychosis in a prospective cohort study: cause, effect, and directionality. American Journal of Psychiatry 170, 734-741.

Kendler KS, Lieberman JA, Walsh D (1989). The Structured Interview for Schizotypy (SIS): a preliminary report. Schizophrenia Bulletin 15, 559-571.

Korver N, Quee PJ, Boos H, Simons CJ, Haan L (2012). Genetic Risk and Outcome of Psychosis (GROUP), a multi-site longitudinal cohort study focused on geneenvironment interaction: objectives, sample characteristics, recruitment and assessment methods. International Journal of Methods in Psychiatric Research 21, 205-221.

Leverich GS, McElroy SL, Suppes T, Keck PE Jr., Denicoff KD, Nolen WA, Altshuler LL, Rush AJ, Kupka R, Frye MA (2002). Early physical and sexual abuse associated with an adverse course of bipolar disorder. Biological Psychiatry 51, 288-297.
Lysaker P, Beattie NL, Strasburger AM, Davis LW (2005). Reported history of child sexual in schizophrenia: associations with heightened symptoms levels and poorer participation over four months in vocational rehabilitation. Journal of Nervous and Mental Disease 193, 790-795.

Mackie CJ, Castellanos-Ryan N, Conrod PJ (2011). Developmental trajectories of psychotic-like experiences across adolescence: impact of victimization and substance use. Psychological Medicine 41, 47-58.

Matheson SL, Shepherd AM, Laurens KR, Carr VJ (2011). A systematic meta-review grading the evidence for non-genetic risk factors and putative antecedents of schizophrenia. Schizophrenia Research 133, 133-142.

Matheson SL, Shepherd AM, Pinchbeck RM, Laurens KR, Carr VJ (2013). Childhood adversity in schizophrenia: a systematic meta-analysis. Psychological Medicine 43, 225-238.

Maxwell ME (1992). Manual for the FIGS (Family Interview for Genetic Studies). Clinical Neurogenetics Branch, Intramural Research Program, National Institute of Mental Health: Bethesda, MD.

Morgan C, Charalambides M, Hutchinson and Murray $R$ (2010). Migration, ethnicity and psychosis: toward a sociodevelopmental model. Schizophrenia Bulletin 36, 655-664.

Morgan C, Fisher H (2007). Environment and schizophrenia: environmental factors in schizophrenia: childhood trauma - a critical review. Schizophrenia Bulletin 33, 3-10.

Morrison AP, Frame L, Larkin W (2003). Relationships between trauma and psychosis: a review and integration. British Journal of Clinical Psychology 42, 331-353.

Neria Y, Bromet EJ, Carlson GA, Naz B (2005). Assaultive trauma and illness course in psychotic bipolar disorder: findings from the Suffolk county mental health project. Acta Psychiatrica Scandinavica 111, 380-383.

Perry BD, Beauchaine T, Hinshaw S (2008). Child maltreatment: a neurodevelopmental perspective on the role of trauma and neglect in psychopathology. In Child and Adolescent Psychopathology (ed. T. P. Beauchaine and S. P. Hinshaw), pp. 93-128. Wiley \& Sons: Hoboken, NJ.

Pocock SJ, Assmann SE, Enos LE, Kasten LE (2002). Subgroup analysis, covariate adjustment and baseline comparisons in clinical trial reporting: current practice and problems. Statistics in Medicine 21, 2917-2930.

Rabinowitz J, De Smedt G, Harvey PD, Davidson M (2002). Relationship between premorbid functioning and symptom severity as assessed at first episode of psychosis. American Journal of Psychiatry 159, 2021-2026.

Read J, Gumley A (2008). Can attachment theory help explain the relationship between childhood adversity and psychosis? Attachment: New Directions in Psychotherapy and Relational Psychoanalysis 2, 1-35.

Ross CA, Anderson G, Clark P (1994). Childhood abuse and the positive symptoms of schizophrenia. Hospital and Community Psychiatry 45, 489-491.

Schreier A, Wolke D, Thomas K, Horwood J, Hollis C, Gunnell D, Lewis G, Thompson A, Zammit S, Duffy L (2009). Prospective study of peer victimization in childhood and psychotic symptoms in a nonclinical population at age 12 years. Archives of General Psychiatry 66, 527-536. 
Thombs BD, Bernstein DP, Lobbestael J, Arntz A (2009). A validation study of the Dutch Childhood Trauma Questionnaire-Short Form: factor structure, reliability, and known-groups validity. Child Abuse and Neglect 33, 518-523. van Nierop $M$, van Os J, Gunther N, Myin-Germeys I, de Graaf R, ten Have M, van Dorsselaer S, Bak M, van Winkel R (2012). Phenotypically continuous with clinical psychosis, discontinuous in need for care: evidence for an extended psychosis phenotype. Schizophrenia Bulletin 38, 231-238.

van Winkel R, Kahn RS, Linszen DH, van Os J, Wiersma D, Bruggeman R, Cahn W, de Haan L, Krabbendam L, Myin-Germeys I (2010). Family-based analysis of genetic variation underlying psychosis-inducing effects of cannabis: sibling analysis and proband follow-up. Archives of General Psychiatry 68, 148-157.

van Winkel R, van Nierop M, Myin-Germeys I, van Os J

(2013). Childhood trauma as a cause of psychosis: linking genes, psychology and biology. Canadian Journal of Psychiatry 58, 44-51.

Varese F, Smeets F, Drukker M, Lieverse R, Lataster T, Viechtbauer W, Read J, van Os J, Bentall RP (2012). Childhood adversities increase the risk of psychosis: a meta-analysis of patient-control, prospective- and cross-sectional cohort studies. Schizophrenia Bulletin 38, 661-671.
Vollema MG, Ormel J (2000). The reliability of the Structured Interview for Schizotypy-Revised. Schizophrenia Bulletin 26 619-629.

Vollema MG, Postma B (2002). Neurocognitive correlates of schizotypy in first degree relatives of schizophrenia patients. Schizophrenia Bulletin 28, 367-378.

Walker EF, Diforio D (1997). Schizophrenia: a neural diathesis-stress model. Psychological Review 104, 667-685.

Wechsler D (1997). Wechsler Adult Intelligence Scale-III (WAIS-III). Psychological Corporation: San Antonio, TX.

WHO (1990). Composite International Diagnostic Interview (CIDI), Version 1.0. World Health Organization: Geneva.

Wigman JTW, van Winkel R, Raaijmakers QAW, Ormel J, Verhulst FC, Reijneveld SA, van Os J, Vollebergh WAM (2011). Evidence for a persistent, environment-dependent and deteriorating subtype of subclinical psychotic experiences: a 6-year longitudinal general population study. Psychological Medicine 41, 2317-2329.

Wing JK, Babor T, Brugha T, Burke J, Cooper J, Giel R, Jablenski A, Regier D, Sartorius N (1990). SCAN. Schedules for Clinical Assessment in Neuropsychiatry. Archives of General Psychiatry 47, 589-593.

Zlotnick C, Ryan CE, Miller IW, Keitner GI (1995). Childhood abuse and recovery from major depression. Child Abuse and Neglect 19, 1513-1516. 